\title{
Meningkatkan Rasa Percaya Diri Mahasiswa dalam Speaking English Melalui Kegiatan English BootCamp
}

\author{
Roudlotun Nurul Laili ${ }^{1}$, Muhammad Nashir ${ }^{2 *}$ \\ ${ }^{1}$ Program Studi DIII Keperawatan, Stikes Banyuwangi \\ ${ }^{2}$ Program Studi S1 Keperawatan, Stikes Banyuwangi \\ 11uutnashir996@gmail.com, 2nashirmuhammad123@gmail.com
}

\begin{abstract}
In today's era of globalization, English competence is an essential aspect for the young generation to collaborate and compete globally. This activity is necessary because students often feel reluctant and insecure when communicating by using English in and outside the campus because they are afraid of making mistakes in pronunciation or grammatically. This community service activity aimed to increase students' motivation and self-confidence in Speaking English through the English BootCamp. English BootCamp is an outdoor activity that aims to give students a new atmosphere through more exciting activities. This activity was attended by 60 students who are the new members of Stikes Banyuwangi English Club. The expected outcome was that the students are more motivated to sharpen their skills and confidence in speaking English even though they majored in medicine. The methods used were games, discussion, songs, role play, and Free Talking. Students are very enthusiastic about joining this program because they provide a new experience with an outdoor atmosphere that is more relaxed, not boring, and not monotonous with various fun activity methods. Students become more courageous and have high self-confidence in Speaking English. They are more active in asking questions about vocabulary/expressions they do not understand, and they show their efforts by being actively involved in every activity. English BootCamp activity can change the students' mindset if Speaking English is not as difficult as imagined. This activity not only increases students' motivation and confidence but also their English skills.
\end{abstract}

Keywords: Motivation, Confidence, Speaking English, English BootCamp.

\section{Abstrak}

Di era globalisasi masa kini kompetensi berbahasa Inggris merupakan aspek penting bagi generasi muda agar dapat berkolaborasi dan berkompetisi di pasar global. Kegiatan pengabdian ini sangat perlu dilakukan mengingat mahasiswa seringkali merasa enggan dan tidak percaya diri ketika berkomunikasi menggunakan bahasa Inggris di lingkungan kampus maupun diluar kampus karena mereka takut membuat kesalahan dalam pengucapan maupun secara gramatikal. Tujuan kegiatan pengabdian kepada masyarakat ini untuk rasa percaya diri mahasiswa dalam Speaking English melalui kegiatan English BootCamp. English BootCamp adalah suatu aktivitas outdoor yang bertujuan agar mahasiswa mendapatkan atmosfer baru melalui berbagai jenis kegiatan yang lebih menarik. Kegiatan ini diikuti oleh 60 mahasiswa yang tergabung sebagai member baru English Club Stikes Banyuwangi. Luaran yang diharapkan adalah mahasiswa lebih termotivasi untuk mengasah kemampuannya dan lebih percaya diri berkomunikasi menggunakan bahasa Inggris meskipun mereka kuliah di jurusan medis. Metode yang digunakan antara lain game, diskusi, lagu, role play dan Free Talking. Mahasiswa sangat antusias mengikuti program ini karena memberikan pengalaman baru dengan suasana outdoor yang lebih rileks, tidak membosankan, dan tidak monoton dengan beragam metode kegiatan yang menyenangkan. Mahasiswa menjadi lebih berani dan memiliki rasa percaya diri yang tinggi dalam Speaking English, mereka lebih aktif bertanya tentang kosakata/ungkapan yang tidak mereka pahami, mereka menunjukkan usahanya dengan terlibat aktif dalam setiap aktivitas. Kegiatan English BootCamp mampu mengubah mindset mahasiswa bahwa Speaking English itu tidak sesulit yang dibayangkan. Kegiatan ini tidak hanya meningkatkan motivasi dan rasa percaya diri mahasiswa tetapi juga kemampuan bahasa Inggris mereka. 
Kata Kunci: Motivasi, Percaya Diri, Speaking English, English BootCamp.

*Penulis Korespondensi: Muhammad Nashir

\section{PENDAHULUAN}

Di era globalisasi pada masa kini kompetensi berbahasa Inggris merupakan salah satu aspek penting, terutama bagi generasi muda, agar dapat berkolaborasi atau berkompetisi di pasar global. Kebutuhan akan pentingnya kemampuan berbahasa Inggris mendorong setiap individu untuk berkeinginan mempelajari dan berlatih bahasa Inggris baik secara formal ataupun informal. Agar dapat mempersiapkan diri sebagai tenaga kerja yang terampil dan kompetitif dalam dunia kerja nasional ataupun internasional, mahasiswa perlu diberikan motivasi belajar bahasa asing terutama bahasa Inggris sebagai bahasa Internasional yang mendunia.

Meskipun bahasa Inggris sudah masuk sebagai mata kuliah wajib umum (MKWU) yang wajib diampu oleh mahasiswa di ranah perguruan tinggi, tetapi masih dianggap materi yang sangat sulit dan paling tidak diminati. Motivasi mereka untuk mengasah kemampuan berbahasa Inggris masih rendah. Berdasarkan pengamatan dan wawancara tidak terstruktur terhadap beberapa mahasiswa ada berbagai kendala yang dihadapi oleh mereka saat Speaking English diantaranya merasa merasa kurang percaya diri karena takut melakukan kesalahan dalam pengucapan maupun struktur tata bahasanya. Hal ini menjadi kendala yang paling umum terjadi di kalangan mahasiswa sehingga mereka enggan dan malu - malu untuk berkomunikasi menggunakan bahasa Inggris baik di dalam maupun di luar kampus.

Disamping itu kurang adanya forum/even dan lingkungan yang tepat yang mampu mendukung mahasiswa agar lebih percaya diri dalam berkomunikasi menggunakan bahasa Inggris, sehingga Stikes Banyuwangi yang nota bene kampus kesehatan memfasilitasi mahasiswa yang ingin meningkatkan kemampuan bahasa Inggrisnya dengan membentuk Unit Kegiatan Mahasiswa (UKM) English Club sebagai wadah untuk mereka. Bagaimanapun mahasiswa perlu mengasah terus skill bahasa Inggrisnya guna menunjang profesinya di masa depan sehingga mampu menjadi tenaga medis profesional yang mampu berdaya saing secara global sesuai dengan visi misi Stikes Banyuwangi.

Salah satu upaya peningkatan motivasi dan rasa percaya diri mahasiswa yang ditawarkan oleh UKM
English Club Stikes Banyuwangi adalah melalui program pendidikan dan pelatihan untuk mahasiswa baru yang sudah mendaftar dan bergabung menjadi member baru UKM English Club Stikes Banyuwangi yaitu sebuah program fresh dan inovatif berupa kegiatan English BootCamp. English BootCamp adalah suatu aktivitas outdoor yang bertujuan agar mahasiswa mendapatkan atmosfer baru dalam peningkatan penguasaan bahasa Inggris melalui berbagai jenis kegiatan yang lebih atraktif dan menyenangkan. Mahasiswa bisa belajar dengan suasana nyaman, tidak tegang, informal sehingga mereka merasa free, tidak terbebani dan berani bertanya serta mengutarakan pendapatnya tanpa merasa canggung.

Materi dan format pelatihan tentunya disesuaikan dengan kebutuhan penggunaan bahasa itu sendiri yaitu lebih fokus pada kemampuan Speaking. English BootCamp merupakan sebuah terobosan baru yang kegiatannya menekankan pada Speaking skill, hal ini menjadi momen dan kesempatan yang sangat bagus bagi mahasiswa untuk mempratikkan apa yang sudah mereka pelajari (Mustakim and Ismail, 2018). English BootCamp adalah strategi untuk menumbuhkan kembali motivasi mahasiswa dan memupuk rasa percaya diri mereka dalam Speaking skill melalui penambahan kosa kata, menyusun kalimat, dan pelafalan dalam bahasa Inggris dengan benar menggunakan metode yang mengasyikkan sehingga menarik perhatian mahasiswa dan merubah pola pikir mereka jika Bahasa Inggris itu sulit.

Konsep kegiatan ini adalah Speaking English outdoor dengan mengambil lokasi yang nyaman dan asri dengan jarak tidak terlalu jauh dari kampus dan mudah dijangkau kendaraan. Dalam mengikuti serangkaian kegiatan English BootCamp ini mahasiswa diwajibkan berkomunikasi menggunakan bahasa Inggris sepanjang hari dengan teman sejawat, kakak pendamping senior, dan para tutor. Jika mereka keceplosan menggunakan bahasa Indonesia maka akan dikenakan punishment. Hal ini menjadi tantangan tersendiri bagi mahasiswa karena tidak semua mahasiswa baru yang tergabung dalam member UKM English Club sudah lancar berbahasa Inggris, banyak dari mereka yang kemampuannya masih dibawah standar. English Camp memberi kesempatan bagi mahasiswa untuk berinteraksi menggunakan bahasa Inggris secara natural 
dan otentik dengan lingkungan dan relasi baru dari berbagai jurusan (Kurniawan and Fussalam, 2020).

Luaran yang diharapkan dari kegiatan English BootCamp yang dikemas dengan konsep menarik ini antara lain 1) mahasiswa baru Stikes Banyuwangi lebih termotivasi untuk mengasah kemampuannya di bidang bahasa Inggris meskipun mereka kuliah di jurusan medis, 2) mahasiswa lebih percaya diri ketika Speaking English dan memaksimalkan potensi yang telah mereka miliki, 3) Mahasiswa mampu berbicara bahasa Inggris di depan publik dengan baik dan percaya diri, dan 4) mampu menunjang karir tenaga medis di dunia kerja dan mampu berdaya saing di kancah Internasional.

Dari berbagai permasalah yang dipaparkan diatas terkait rasa tidak percaya diri dan kurangnya motivasi dari dalam diri mahasiswa maka kegiatan English BootCamp bisa menjadi solusi efektif dengan gaya pembelajaran outdoor, santai, dan informal dengan beragam kegiatan menarik dilengkapi dengan games sehingga mahasiswa merasakan atmosfer yang nyaman yaitu konsep belajar sambil bermain yang sangat menyenangkan.

\section{METODE}

Bahasa Inggris di ranah perguruan tinggi masih dianggap materi yang sangat sulit dan paling tidak diminati mahasiswa. Mahasiswa kurang termotivasi untuk mengasah kemampuan berbahasa Inggrisnya. Berbagai kendala dihadapi oleh mahasiswa saat Speaking English seperti merasa kurang percaya diri karena takut melakukan kesalahan, minimnya penguasaan kosa kata dan tata bahasa atau gramatikal sehingga mereka lebih memilih diam daripada harus menanggung malu saat berbicara bahasa Inggris dengan banyak kesalahan.

Dari berbagai permasalahan yang muncul, kami menggagas acara Stikes Banyuwangi English Bootcamp (SBEB) 2020 dengan mengundang beberapa pembicara (speakers) agar dapat berbagi ilmu dan pengalamannya, memberikan motivasi, wawasan dan edukasi mengenai pentingnya penguasaan dan komunikasi menggunakan bahasa Inggris dalam menghadapi era global serta menunjang karir sebagai tenaga medis profesional agar tidak tertinggal dengan negara - negara maju lainnya sehingga mahasiswa lebih termotivasi untuk pantang menyerah dalam mengasah skill berbahasa Inggris. Ada beragam metode kegiatan yang bisa digunakan diantaranya game, diskusi, lagu, role play dan Free Talking.

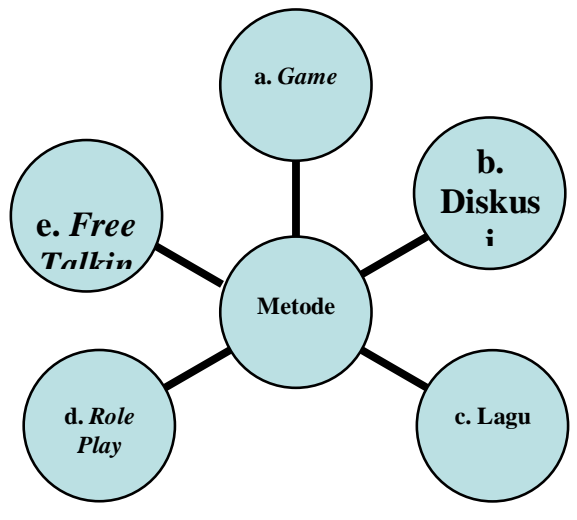

Gambar 1. Metode Kegiatan Pengabdian

\section{a. Game}

Game adalah sebuah hiburan yang sering digunakan untuk merefresh otak dari rasa penat karena berbagai rutinitas dan akitivitas (Harsono, 2015). Game yang digunakan dalam kegiatan ini adalah berbagai macam permainan edukatif yang fun dan melibatkan seluruh peserta untuk berpartisipasi aktif. Permainan ini bertujuan untuk menambah vocabulary mahasiswa. Aneka permainan yang digunakan seperti puzzle, guess word, brainstorming, bingo, flashcard, simon says, dan pseudonym game. Permainan tersebut berguna untuk mengasah otak dan mempertajam memori mahasiswa dalam menghafal serta mengingat kosa kata tanpa merasa dipaksa karena konsepnya menyenangkan yaitu bermain dan belajar.

Semakin banyak kosa kata yang dimiliki mahasiswa, maka akan semakin mudah berkomunikasi menggunakan Bahasa Inggris, jadi elemen utamanya adalah kosa kata yang menjembatani mereka untuk terampil dalam Speaking English. Pemilihan berbagai jenis dan bentuk games harus sesuai dengan kebutuhan peserta didik sehingga tujuan pembelajaran bisa tercapai dengan maksimal. Penggunaan games tidak hanya mampu memotivasi para siswa tetapi juga menumbuhkan minat dan keinginan mereka untuk menggunakan bahasa yang mereka pelajari (Bakhsh, 2016).

b. Diskusi

Diskusi yaitu percakapan aktif seperti sharing pendapat, munculnya bermacam - macam pertanyaan dan ide - ide yang dilaksanakan oleh sebagian kelompok dan diharapkan mampu mendapatkan solusi dan memecahkan permasalahan (Sagala, 2009). Dalam kegiatan diskusi 
mahasiswa dibagi dalam kelompok - kelompok kecil yang terdiri dari $4-6$ orang dan tema diskusi sudah ditentukan oleh tutor. Mahasiswa dapat mengutarakan pendapat dan gagasan mengenai suatu kejadian yang sedang trending sebagai tema diskusi serta menawarkan solusi terbaik dari beragam peristiwa yang didiskusikan.

Tujuan kegiatan diskusi adalah untuk memancing ide mahasiswa, mendorong mereka agar mampu mengutarakan gagasan dan berani mengajukan pertanyaan dalam situasi yang nyaman dan tidak tegang seperti saat curhat dengan kawan - kawannya. Diskusi membentuk kebiasaan mahasiswa agar mampu bekerja dengan banyak orang dengan berbagai karakter dan mampu menerima serta terbuka terhadap gagasan yang berbeda sehingga secara tidak langsung mampu menumbuhkan rasa percaya diri mahasiswa dalam berkomunikasi dengan publik secara luas dan menghargai perbedaan.

\section{c. Lagu}

Menyanyikan lagu memberikan manfaat positif diantaranya menambah kosa kata, meningkatkan ingatan pada memori otak, menumbuhkan rasa percaya diri, menurunkan tingkat stress, dan menjadikan pikiran lebih fresh (Rokhmah, Suryandari and Wahyudi, 2017). Menyanyikan lagu adalah sesuatu hal yang sangat menyenangkan bagi siapapun, termasuk mahasiswa. Ketika bernyanyi mereka mendendangkan lirik dengan riang tanpa beban sehingga lagu cocok digunakan sebagai salah satu alternatif dalam kegiatan pembelajaran bahasa Inggris. Dengan bernyanyi mahasiswa secara otomatis mempelajari beberapa sIkill sekaligus yaitu listening, speaking, pronounciation, dan penambahan kosa kata baru.

\section{d. Role Play}

Role Play adalah bagian dari aspek aktivitas simulasi yang mana para pelajar memainkan peran dalam situasi yang sudah ditentukan (Mustadi, 2015). Aktivitas ini mendorong mahasiswa agar saling berinteraksi satu sama lain untuk meningkatkan kemampuan Speaking English. Para tutor memberikan konteks atau topik, lalu mahasiswa mengambil peran yang beragam sesuai konteksnya. Jadi tutor memberikan arahan kepada mahasiswa jika mereka harus memainkan peran sebagai tokoh dengan karakter tertentu. Kegiatan ini bisa melibatkan 2 - 5 mahasiswa.

\section{e. Free Talking}

Free Talking adalah kegiatan berkomunikasi antar sesama peserta menggunakan bahasa Inggris yang dilakukan secara berpasangan dengan tema yang sudah ditentukan dan dipantau oleh LO untuk membantu jika peserta mengalami kesulitan dalam kosa kata, pengucapan maupun penyusunan kalimat/ungkapan yang benar. Free Talking juga bisa berupa kegiatan conversation antar peserta selama kegiatan berlangsung sepanjang hari ketika di Camp karena selama kegiatan mahasiswa diwajibkan Speaking English secara total.

Prosedur kegiatan pengabdian berupa atan motivasi dan rasa percaya diri mahasiswa dalam Speaking English melalui English BootCamp antara lain:

1. Persiapan kegiatan meliputi pendataan member baru UKM English Club Stikes Banyuwangi.

2. Rapat koordinasi pengurus dan Pembina UKM English Club untuk menggagas kegiatan English BootCamp.

3. Sosialisasi program kepada ketua BEM, Wakil Ketua Bidang III bagian kemahasiswaan, Ketua Lembaga Pengabdian Masyarakat Stikes Banyuwangi, dan Ketua Stikes Banyuwangi

4. Membuat proposal kegiatan, mengurus surat izin, membuat surat permohonan Speaker yang diundang dalam English BootCamp dan meminta surat perintah tugas untuk melaksanakan kegiatan pengabdian kepada pihak PPPM Stikes Banyuwangi.

5. Menyiapkan tempat dan peralatan yang dibutuhkan dalam kegiatan English BootCamp.

6. Menyusun acara, materi, dan kegiatan - kegiatan yang mendorong mahasiswa Speaking English.

7. Melaksanakan kegiatan sesuai rundown acara.

8. Monitoring dan evaluasi kegiatan yang telah

9. Menyusun laporan kegiatan

10. Secara continue memfasilitasi mahasiswa untuk berkomunikasi aktif menggunakan bahasa Inggris melalui wadah UKM English Club.

\section{HASIL DAN PEMBAHASAN}

Dengan melihat kondisi riil di lapangan banyak mahasiswa yang enggan dan tidak percaya diri untuk Speaking English maka UKM English Club Stikes Banyuwangi menggagas acara Stikes Banyuwangi English BootCamp dengan mengundang beberapa pembicara dan para tutor berpengalaman untuk dapat memberikan motivasi, wawasan dan edukasi mengenai pentingnya penguasaan dan komunikasi menggunakan bahasa Inggris dalam menghadapi era global serta menunjang karir sebagai tenaga medis profesional agar tidak tertinggal 
dengan Negara - Negara maju lainnya sehingga mahasiswa lebih termotivasi untuk pantang menyerah dalam mengasah skillnya berbahasa Inggris. Berikut hasil dari berbagai kegiatan serangkaian English BootCamp beserta dampaknya bagi mahasiswa:

Tabel 1. Kegiatan English BootCamp dan dampaknya

\begin{tabular}{|c|l|l|}
\hline \multicolumn{1}{|c|}{$\begin{array}{c}\text { Nama Kegiatan } \\
\text { kosa kata }\end{array}$} & Metode & \multicolumn{1}{|c|}{ Dampak } \\
\hline $\begin{array}{l}\text { 2. Sharing } \\
\text { pendapat }\end{array}$ & $\begin{array}{l}\text { Kosa kata bahasa } \\
\text { Inggris mahasiswa } \\
\text { meningkat. }\end{array}$ \\
\hline $\begin{array}{l}\text { 3. Merelaksasi } \\
\text { otak }\end{array}$ & $\begin{array}{l}\text { Pengetahuan umum } \\
\text { dan kemampuan } \\
\text { Speaking English } \\
\text { mahasiswa meningkat. }\end{array}$ \\
\hline $\begin{array}{l}\text { 4. Memainkan } \\
\text { peran sesuai } \\
\text { karakter }\end{array}$ & Role Play & $\begin{array}{l}\text { Kosa kata bertambah } \\
\text { dan pronounciation } \\
\text { lebih bagus. }\end{array}$ \\
\hline $\begin{array}{l}\text { 5. Komunikasi } \\
\text { sepanjang hari } \\
\text { di Camp }\end{array}$ & Free & $\begin{array}{l}\text { Kalking } \\
\text { memasiswa meningkat }\end{array}$ \\
\hline
\end{tabular}

Kegiatan English BootCamp dilaksanakan pada hari Sabtu dan Minggu tanggal 29 Februari - 1 Maret 2020 yang diikuti oleh 60 peserta dengan 12 kakak pendamping senior sebagai Liaison Officer (LO) yang bertanggung jawab untuk memantau dan membantu berlangsungnya acara ini. Berikut rundown acara English BootCamp:

Tabel 2. Jadwal Kegiatan hari Pertama

Sabtu, 29 Februari 2020

\begin{tabular}{|c|l|c|l|}
\hline JAM & KEGIATAN & Co & \multicolumn{1}{|c|}{ Ket } \\
\hline $\begin{array}{l}07.00- \\
07.30\end{array}$ & Registrasi & Ardhika & Pembagian \\
& & Pramana & $\begin{array}{l}\text { ID Card, } \\
\text { PIN, } \\
\text { Kelompok } \\
\text { dan Kamar }\end{array}$ \\
\hline $\begin{array}{l}07.30- \\
08.00\end{array}$ & $\begin{array}{l}\text { Menuju Camp } \\
\text { Griya Ekologi } \\
\text { Kelir }\end{array}$ & LO & $\begin{array}{l}\text { Menuju } \\
\text { Kamar }\end{array}$ \\
\hline $\begin{array}{l}08.00- \\
09.00\end{array}$ & $\begin{array}{l}\text { Opening } \\
\text { Ceremony }\end{array}$ & Sie Acara & Baju Batik \\
\hline $\begin{array}{l}09.00- \\
10.30\end{array}$ & Materi 1 & Roudlotun & Di Aula \\
\hline $\begin{array}{l}10.30- \\
11.30\end{array}$ & Vocabulary & Lame (spelling, & $\begin{array}{l}\text { Dibagi } \\
\text { kelompok }\end{array}$ \\
\hline
\end{tabular}

\begin{tabular}{|c|c|c|c|}
\hline JAM & KEGIATAN & Co & Ket \\
\hline & $\begin{array}{l}\text { pseudonym, dan } \\
\text { simon says } \\
\text { game) }\end{array}$ & & \\
\hline $\begin{array}{l}11.30- \\
13.00\end{array}$ & ISHOMA & $\mathrm{LO}$ & \\
\hline $\begin{array}{l}13.00- \\
14.30\end{array}$ & $\begin{array}{l}\text { Kiat mudah } \\
\text { Speaking } \\
\text { English } \\
\text { (Pronounciation } \\
\text { \& Listening) }\end{array}$ & $\begin{array}{l}\text { Muhamma } \\
\text { d Nashir }\end{array}$ & $\begin{array}{l}\text { Aula } \\
\text { Pakaian } \\
\text { bebas rapi }\end{array}$ \\
\hline $\begin{array}{l}14.30- \\
16.00\end{array}$ & $\begin{array}{l}\text { Sharing Session } \\
\text { (Diskusi) }\end{array}$ & $\mathrm{LO}$ & $\begin{array}{l}\text { Lotre } \\
\text { Kelompok } \\
\text { dan Topik } \\
\text { diskusi }\end{array}$ \\
\hline $\begin{array}{c}16.00- \\
19.0\end{array}$ & ISHOMA & L.O & \\
\hline $\begin{array}{c}19.00- \\
20.00\end{array}$ & $\begin{array}{l}\text { Membuat yel } \\
\text { yel dan } \\
\text { persiapan } \\
\text { performing arts }\end{array}$ & LO & $\begin{array}{l}\text { Sesuai } \\
\text { pembagian } \\
\text { kelompok }\end{array}$ \\
\hline $\begin{array}{c}20.00- \\
22.00\end{array}$ & $\begin{array}{l}\text { Performing Arts } \\
\text { (Sing a Song) \& } \\
\text { Api Unggun }\end{array}$ & Sie Acara & $\begin{array}{l}\text { Pertunjukan } \\
\text { seni setiap } \\
\text { kelompok }\end{array}$ \\
\hline 22.00 & Tidur & L.O & \\
\hline
\end{tabular}

Tabel 3. Jadwal Kegiatan hari Kedua

\begin{tabular}{|c|c|c|c|}
\hline JAM & KEGIATAN & Co & Ket \\
\hline $\begin{array}{l}04.00- \\
05.00\end{array}$ & Sholat Subuh & $\begin{array}{l}\text { Dayat } \\
\text { Rima }\end{array}$ & \\
\hline $\begin{array}{l}05.00- \\
05.30\end{array}$ & $\begin{array}{l}\text { Ant Operation } \\
\text { (Walking Around) }\end{array}$ & $\mathrm{LO}$ & \\
\hline $\begin{array}{l}05.30- \\
06.00\end{array}$ & Senam Pagi & $\begin{array}{l}\text { Ikhlas } \\
\text { Bekti }\end{array}$ & $\begin{array}{l}\text { Kaos } \\
\text { olahraga }\end{array}$ \\
\hline $\begin{array}{l}06.00- \\
07.30\end{array}$ & $\begin{array}{l}\text { Mandi, Persiapan } \\
\text { dan Sarapan }\end{array}$ & $\mathrm{LO}$ & $\begin{array}{l}\text { Membersihk } \\
\text { an Camp } \\
\text { Free Talking }\end{array}$ \\
\hline $\begin{array}{l}07.30- \\
09.00\end{array}$ & $\begin{array}{l}\text { Grammar for } \\
\text { Speaking }\end{array}$ & $\begin{array}{l}\text { Naufal } \\
\text { Anfal }\end{array}$ & \\
\hline $\begin{array}{l}09.00- \\
10.30\end{array}$ & $\begin{array}{l}\text { Game (puzzle, } \\
\text { guess word, } \\
\text { brainstorming, } \\
\text { bingo, flashcard) }\end{array}$ & LO & \\
\hline $\begin{array}{l}10.30- \\
12.00\end{array}$ & $\begin{array}{l}\text { Professional } \\
\text { Meeting \& Public } \\
\text { Speaking }\end{array}$ & $\begin{array}{l}\text { Riska } \\
\text { Regita }\end{array}$ & $\begin{array}{l}\text { Aula } \\
\text { Pakaian } \\
\text { bebas rapi }\end{array}$ \\
\hline $\begin{array}{l}12.00- \\
13.00\end{array}$ & ISHOMA & LO & \\
\hline $\begin{array}{l}13.00- \\
14.30\end{array}$ & $\begin{array}{l}\text { Scholarship \& } \\
\text { Sharing } \\
\text { Experience } \\
\text { Session }\end{array}$ & Masroni & $\begin{array}{l}\text { Aula } \\
\text { Pakaian } \\
\text { bebas rapi }\end{array}$ \\
\hline
\end{tabular}




\begin{tabular}{|l|l|c|l|}
\hline \multicolumn{1}{|c|}{ JAM } & KEGIATAN & Co & \multicolumn{1}{|c|}{ Ket } \\
\hline $\begin{array}{l}14.30- \\
15.00\end{array}$ & Eyesbreaking & $\begin{array}{c}\text { Sie } \\
\text { Acara }\end{array}$ & \\
\hline $\begin{array}{l}15.00- \\
16.00\end{array}$ & Istirahat+Sholat & LO & Packing \\
\hline $\begin{array}{l}16.00- \\
17.30\end{array}$ & Free Talking & LO & \\
\hline $\begin{array}{l}17.30- \\
18.30\end{array}$ & ISHOMA & LO & \\
\hline $\begin{array}{l}18.30- \\
20.30\end{array}$ & Role Play & LO & \\
\hline $20.30-$ & $\begin{array}{l}\text { Awarding Session } \\
21.00\end{array}$ & Rafica & $\begin{array}{l}\text { Pengumuma } \\
\text { E Closing yel, tim } \\
\text { dan peserta } \\
\text { terbaik }\end{array}$ \\
\hline 21.00 & Pulang (Sayonara) & LO & $\begin{array}{l}\text { Dijemput } \\
\text { Orang Tua }\end{array}$ \\
\hline
\end{tabular}

Dalam kegiatan English BootCamp ini kami selaku dosen pembina berkolaborasi dengan mahasiswa Stikes Banyuwangi yang tergabung dalam UKM SBEC (Stikes Banyuwangi English Club) untuk mendampingi para juniornya dalam berkomunikasi dan berinteraksi menggunakan bahasa Inggris. Kami juga mengundang beberapa pembicara sebagai pengisi acara guna sharing ilmu dan pengalamannya sehingga meningkatkan motivasi mahasiswa untuk terus mengasah kemampuannya dalam bahasa Inggris.

Pada hari pertama mahasiswa mendapatkan ID card dan PIN, pembagian kamar, tim dan koin coklat yang wajib dibawa setiap saat. Salah satu kewajiban peserta adalah wajib menggunakan bahasa Inggris saat berkomunikasi dengan teman sejawat, kakak pendamping dan tutor. Ketika mereka keceplosan menggunakan bahasa Indonesia, melakukan pelanggaran, terlambat dalam kegiatan maka koin akan diambil 1. Jika mereka aktif bertanya dan aktif dalam kegiatan maka akan mendapatkan koin coklat. Pada akhir acara akan direkap mahasiswa yang mendapatkan koin coklat terbanyak akan dinobatkan sebagai peserta terbaik dan mahasiswa dengan koin paling sedikit akan mendapatkan punishment yaitu menampilkan performa bisa berupa sing a song, membaca puisi, pantun, telling story atau yang lainnya.

Kegiatan Opening Ceremony oleh Wakil Ketua III Bidang Kemahasiswaan, sambutan dari Ketua Stikes Banyuwangi, dan pembacaan tata tertib selama kegiatan oleh panitia. Waka III dan Ketua Stikes Banyuwangi menyampaikan harapannya agar mahasiswa terus berupaya menggali potensi yang ada pada dirinya termasuk dalam
Speaking English karena tenaga medis harus menguasai bahasa Asing agar mampu bersaing dengan tenaga medis lainnya di kancah Internasional. Lalu dilanjutkan dengan materi pertama oleh Mrs. Roudlotun Nurul Laili, salah satu Pembina UKM English Club Stikes Banyuwangi tentang pemberian motivasi dan upaya menumbuhkan rasa percaya diri dalam Speaking English. Pemberian materi guna membuka wawasan mahasiswa untuk tetap teguh pada komitmennya dalam meningkatkan kemampuannya Speaking English.

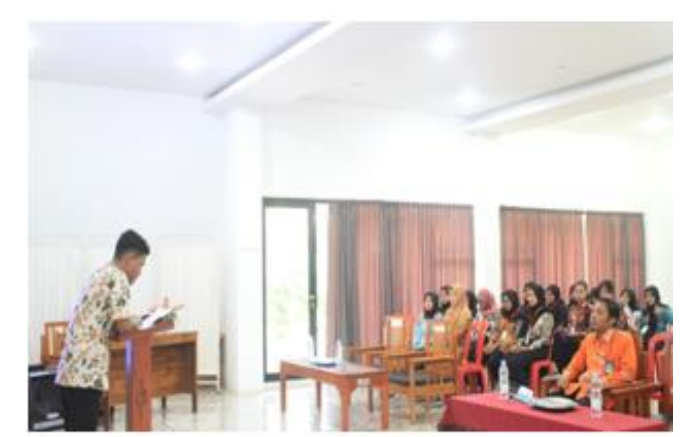

Gambar 2. Opening Ceremony English BootCamp

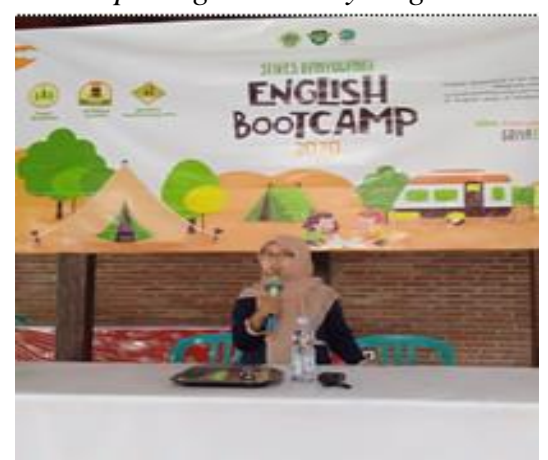

Gambar 3. Pemateri 1 Mrs. Roudlotun Nurul Laili

Setelah materi pertama dilanjutkan dengan permainan kosa kata meliputi (spelling, pseudonym, dan simon says game). Spelling game yaitu permainan mengeja kata. Pseudonym game adalah permainan nama samaran. Mahasiswa harus mengganti namanya dengan nama benda dalam bahasa Inggris, mereka harus menyebutkan nama temannya sesuai dengan nama samarannya. Dan simon says game yaitu permainan dimana seluruh peserta harus mengikuti instruksi dari tutor pendamping atau 1 peserta yang ditunjuk sebagai simon. Jika instruksi diawali dengan kata "simon" maka seluruh peserta wajib melaksanakan instruksi tersebut, tetapi jika instruksi tidak didahului kata "simon" maka peserta dilarang melaksanakan instruksi tersebut. Peserta yang salah diambil koin coklatnya sesuai 
peraturan. Beragam permainan tersebut secara tidak langsung menambah kosa kata mahasiswa.

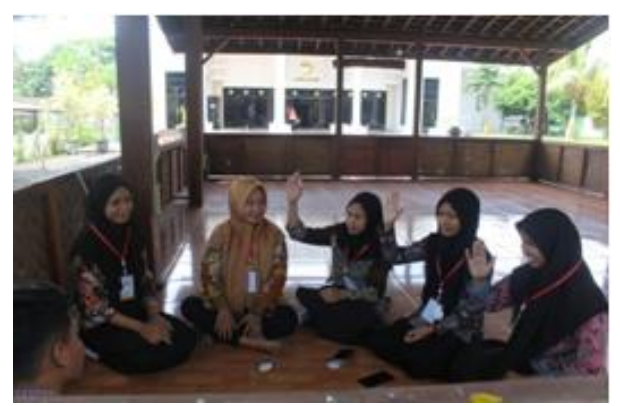

Gambar 4. Game/Permainan Kosa Kata

Materi kedua tentang kiat mudah Speaking English oleh Mr. Muhammad Nashir, hal ini berkaitan erat dengan kemampuan Listening dan pronounciation. Beliau menyampaikan bahwa mempelajari bahasa Inggris bisa melalui lagu maupun film agar telinga kita terbiasa dengan kalimat - kalimat berbahasa Inggris dan lebih mudah untuk menirukan. Jadi semakin sering mendengar, semakin banyak kosa kata, frase, dan kalimat yang bisa kita pelajari.

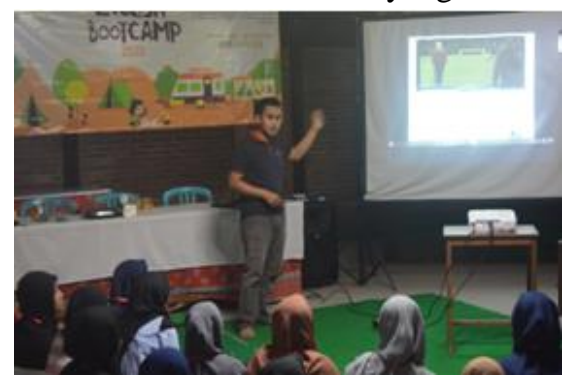

Gambar 5. Pemateri 2 Mr. Muhammad Nashir

Kegiatan berikutnya yaitu diskusi kelompok yang didampingi oleh LO masing - masing. Dalam sesi diskusi mahasiswa sangat aktif karena masing - masing dari mereka wajib mengutarakan pendapatnya mengenai topik hangat yang sedang didiskusikan. Mereka merasa lebih nyaman berdiskusi di ruang terbuka asri dengan suasana yang jauh dari rasa tegang dan takut, mereka berdiskusi dengan santai namun serius sehingga tujuan kegiatan bisa tercapai dengan optimal.

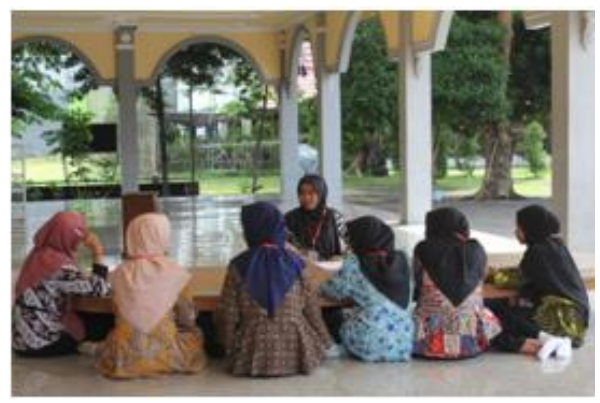

Gambar 6. Diskusi Kelompok Kecil

Kegiatan berikutnya yaitu berdiskusi dengan tim masing - masing untuk membuat yel-yel dan menyiapkan lagu bahasa Inggris yang harus mereka perform pada acara api unggun malam minggu. Semangat mahasiswa berapi api untuk mempersiapkan diri karena mereka ingin menampilkan performa terbaiknya. LO mendampingi dan mengingatkan peserta agar tetap komitmen untuk Speaking English dalam setiap aktivitas. Malam api unggun berjalan lancar dengan sorak sorai peserta menyaksikan penampilan yel-yel dan lagu dari masing - masing tim.

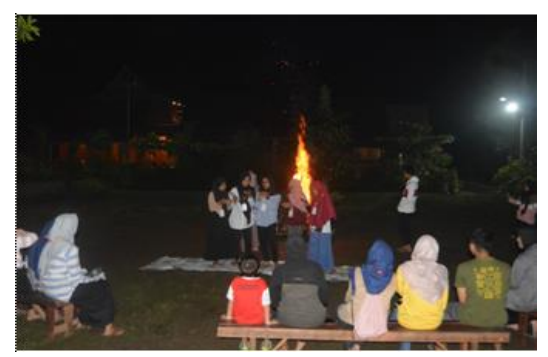

Gambar 7. Performing Art dan Kegiatan Api Unggun

Hari kedua diawali dengan jalan - jalan pagi mengelilingi Griya Ekologi Kelir dan senam agar mahasiswa merasa segar, pikirannya fresh kembali dan siap menerima materi selanjutnya. Materi ketiga Grammar for Speaking disampaikan oleh Mr. Naufal Anfal salah satu tutor di lembaga English Course ternama di Banyuwangi. Materi ini sangat penting bagi peserta karena permasalahan mahasiswa takut untuk Speaking English karena gramatikal, penyusunan kata dan kalimat. Setelah materi ada selingan game agar mahasiswa tidak merasa jenuh yaitu puzzle, guess word, brainstorming, bingo, dan flashcard game yang bertujuan menambah kosa - kata mereka. 


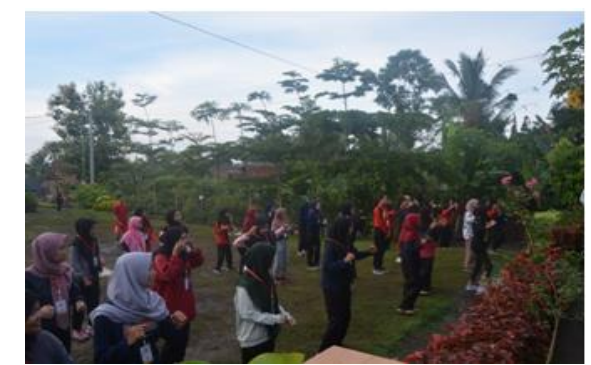

Gambar 8. Senam Sehat Pagi

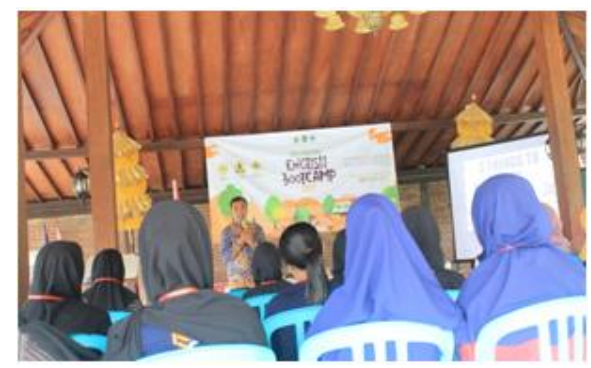

Gambar 9. Pemateri 3 Mr. Naufal Anfal

Kegiatan berikutnya mengenai professional meeting dan public speaking oleh Miss Riska Regita. Public speaking mengasah kemampuan berbicara mahasiswa dengan percaya diri serta melatih berpikir kritis dan kreatif. Materi ini sangat diperlukan karena mahasiswa dituntut berinteraksi dan berkomunikasi aktif dengan publik secara luas serta membangun koneksi dengan banyak orang secara professional. Materi terakhir mengenai Scholarship dan sharing experience session oleh Nurse Masroni, salah satu dosen keperawatan Stikes Banyuwangi yang beberapa tahun lalu menerima beasiswa kuliah S2 di Taiwan. Beliau menyampaikan bahwa dengan memiliki skill bahasa Inggris mahasiswa mendapatkan kesempatan lebih luas untuk mendapatkan beasiswa bergengsi di luar negeri.

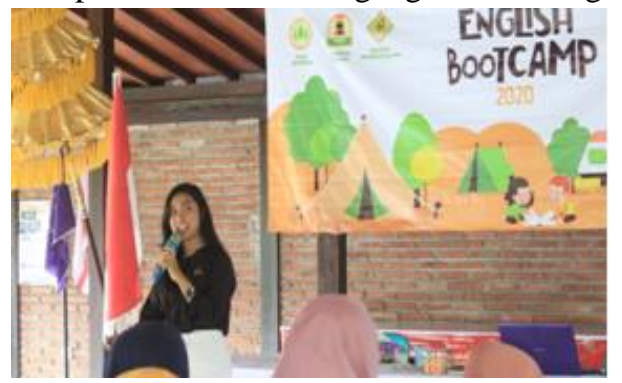

Gambar 10. Public Speaking oleh Ms.Riska

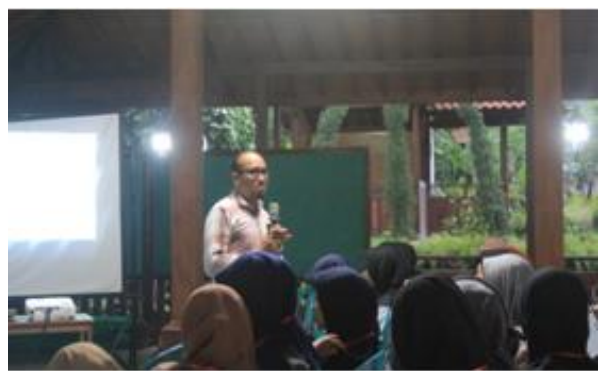

Gambar 11. Scholarship Sharing Session (Mr. Masroni)

Dengan menghadirkan pemateri - pemateri muda berbakat dan berpengalaman menambah motivasi mahasiswa untuk tidak pantang menyerah dan lebih percaya diri dalam Speaking English. Setelah semua materi selesai, panitia memberikan eyesbreaking untuk merelaksasi pikiran mereka dan dilanjutkan dengan Free Talking dengan kelompok dan LO masing masing dengan tema yang sudah ditentukan. Pada sesi ini juga diselipkan pembagian angket yang wajib diisi oleh mahasiswa. Free Talking juga membahas secara singkat tentang pesan dan kesan peserta selama mengikuti kegiatan Stikes Banyuwangi English BootCamp. Kegiatan terakhir di penghujung acara yaitu Role Play (bertukar peran) sesuai dengan tokoh yang sudah ditentukan guna memantapkan dan mengasah Speaking English peserta. Meski sudah terlihat lelah tetapi tidak menyurutkan spirit para peserta berperan aktif pada kegiatan role play ini.

Sebelum penutupan ada kegiatan awarding session pemberian penghargaan terhadap tim terbaik, yel-yel terbaik dan peserta terbaik yang ditandai dengan paling banyaknya memiliki koin coklat. Setelah mendapatkan ilmu dan wawasan baru, motivasi mereka untuk Speaking English semakin kuat, rasa percaya dirinya juga meningkat. Mereka sudah tidak sungkan lagi untuk mengutarakan ide dan gagasannya menggunakan bahasa Inggris meski kadang masih terbata - bata dan harus mencari kata sulit yang tidak diketahui dalam kamus digitalnya.

\section{KESIMPULAN}

Rangkaian kegiatan English BootCamp mampu mengurangi rasa minder mahasiswa akan kemampuan bahasa Inggris mereka yang masih rendah. Kegiatan dengan konsep outdoor yang menyenangkan dengan suasana santai menjadi daya tarik tersendiri bagi mahasiswa untuk belajar dengan nyaman serta membuka 
wawasan dan pengetahuan mereka akan pentingnya bahasa Inggris dalam menyongsong masa depan yang lebih gemilang sehingga secara otomatis menumbuhkan motivasinya. Rasa percaya diri mahasiswa meningkat tanpa ada perasaan takut salah dalam berkomunikasi menggunakan bahasa Inggris. Diharapkan program ini bisa menjadi agenda annual Stikes Banyuwangi dengan durasi waktu yang lebih panjang sehingga memberikan dampak yang lebih optimal bagi mahasiswa.

\section{UCAPAN TERIMAKASIH}

Terima kasih kami ucapkan kepada seluruh pengurus UKM English Club Stikes Banyuwangi yang telah menggagas kegiatan English BootCamp ini. Segenap anggota BEM, Wakil Ketua III Bidang Kemahasiswaan, dan ketua Stikes Banyuwangi yang sangat mendukung penuh kegiatan ini tidak hanya secara moral melainkan juga finansial. Tidak lupa pula uacapan terima kasih sebesar - besarnya kepada para pemateri yang berkenan hadir guna berbagi ilmu, wawasan, dan pengalamannya serta tim Griya Ekologi Kelir yang berkenan menyiapkan tempat, makanan, dan fasilitas memadai sehingga acara English BootCamp bisa berjalan lancar.

\section{DAFTAR PUSTAKA}

Bakhsh, S. A. (2016) 'Using Games as a Tool in Teaching Vocabulary to Young Learners', English Language Teaching, 9(7), pp. 120-128. doi: 10.5539/elt.v9n7p120.

Harsono, M. (2015) Pengaruh Bermain Game terhadap Perkembangan Remaja. Serpong: Surya University.

Kurniawan, R. and Fussalam, Y. E. (2020) 'Meningkatkan Kemampuan Berbicara Bahasa Inggris Dasar melalui Kegiatan English Camp', Jurnal Muara Pendidikan, 5(2), pp. 752-756.

Mustadi, A. (2015) 'Speaking Skill Improvement melalui Role-Playing pada Kompetensi English for Instruction di PGSD', School Education Journal PGSD FIP UNIMED, 3(2), pp. 1-16.

Mustakim and Ismail, I. (2018) 'The Influence of English Camp in Speaking Skill of English House Course Students in Maroangin Kabupaten Enrekang', Edumaspul Jurnal Pendidikan, 2(2), pp. 61-70.

Rokhmah, K., Suryandari, K. C. and Wahyudi (2017)
'Penggunaan Metode Sing a Song dalam Upaya Peningkatan Motivasi dan Hasil Belajar Bahasa Inggris Siswa Kelas IV SDN Tegalsari', Kalam Cendekia, 5(1.1), pp. 36-42.

Sagala, S. (2009) Konsep dan Makna Pembelajaran untuk Memecahkan Problematika Belajar dan Mengajar. Bandung: Alfabeta. 